\title{
Recent Financial Innovations: Have They Distorted the Meaning of M1?
}

\author{
JOHN A. TATOM
}

F ATCHERS and economic policymaker have been sorely taxed by financial innovations in recent years. ${ }^{1}$ Attempts to assess both the appropriate narrow monetary aggregate and its growth have been complicated by the introduction of new types of checkable deposits and new defintions of the narrow aggregate. ${ }^{2}$

In November 1978 , antomatic transfer services (ATS) were legalized nationwide, allowing checkable deposits to be held in savings accounts. In October 1979, the Fed changed its monetary policy procedures to better control the growth of monetary aggregates and, four months later, redefined the monetary aggregates. In January 1981, negotiable onder of withdrawal (NOW) accounts becane legal nationwide. The food of funds to these accounts from demand deposits led to a wide divergence in the growth rates of the newly defined aggregate $M 1 B$, which included both demand deposits and other checkable deposits like ATS and NOW balances, and M1A, which excluded the latter balances.

Further complicating the problem of assessing the growth of a narrow aggregate and its implications, the Board of Govemors of the Federal Reserve System introduced a shift adjustment of MIB in response to the nationwide introduction of NOW accounts. For monetary control, the narrow aggregate target for 1981 was stated in tenms of this new measure by the Federal Open Market Committee. The shift adjustment was intended to remove the distorting effects on MIB growth of shilts of non-

\footnotetext{
See especially, Kemeth $\mathrm{H}$. Bacon, "Fed in a Fix," Wall Strat loumal, Jamatry 22, 1982, for a discussion of recent innovations and some of the confusion felt by policymakers. Also, a general discussion of past finmeial mnovations and the potential problems for measurement and policy can be found in Barbara Bennett and Joseph Bisignano, "Apples, Oranges, and Money: I" and "Apples, Oranges, and Money: II" Federal Reserve Bank of San Francisco Weckly Letter, January 22 and $29,1982$.

2 A narrew aggregate is a measure of the money stock of funds held as media of exchange. A broader aggregate includes, in addition, other highy liquid fands that are held at funacial institations.
}

transactions or savings balances into that aggregate. In January 1982, the distinction between M1A and MIB was dropped so that today one aggregate, M1, is used for a narrow aggregate target. The new MI measure is the same as the MIB measure (not shiftadjusted) used in 1981.

This article examines the effect of the 1981 shift to NOW accounts on the monetary aggregates and its implications. The experience with the introduction of ATS accounts is also reviewed, since some of the issues raised by shilts to NOW accounts applied to ATS.

Whether MLB, shift-adjusted M1B, or M1A is considered the relevant narrow aggregate for monetary policy is important in evaluating the direction of policy. For example, while all three measures slowed in 1981 , the extent of the slowing differed widely. Slower growth of the money stock causes slower growth of total spending in the economy and, after a period of time, reduced inflation. Thus, the extent of slowing in spending and inflation that can be expected from monetary actions in 1981 depends on which measure of the narrow aggregate most closely corresponds to narow aggregate measures that existed prior to the introduction of nationwide NOW accounts.

Clearly, many financial imnovations have concerned economic analysts. None, however, have so affected the measurement and assessment of narrow monetary aggregates as the introduction of $\mathrm{ATS}$ and NOW. In addition, most other innovations generally have predated the changes mentioned above; these other innovations have had greater effects on credit markets and broader monetary aggregates than on the demand and supply of transactions balances. For example, in 1981 considerable attention was paid to the accelenting and above-target growth of the broad aggregate M2 (M1B plus small time and savings, money makket mutual fund shares, overnight repurchase agreements (RPs) at commercial banks, and overnight Enrodollar deposits of U.S. 
nonbank residents at Caribbean branches of member banks), ${ }^{3}$ The $\mathbf{M} 2$ acceleration is related to the grow th of money market mutual funds, an innovation dating back to the early "70s. Neither the growth of M2 nor money market mutual funds is discussed here. ${ }^{4}$

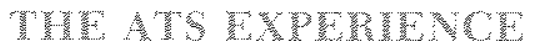

Before the automatic transfer service for savings deposits at commercial banks was introduced, the only transaction accounts at commercial banks that were not classified as demand deposits were NOW accounts in New England. ${ }^{5}$ The shift to ATS accounts had two important effects on the money supply process. First as transactions balances were shifted from demand deposit accounts into ATS accounts, a narrow monetary aggregate like the old M1 or M1A, which both exclude ATS balances, tended to fall; a broader measure stich as current M1 (M1B) or M2, which include ATS balances, was not affected for definitional reasons. ${ }^{6}$

Second, the introduction of ATS changed the total required reserves of commercial banks. Deposits held in ATS accounts at member banks were subject to the required reserve ratio for savings deposits, instead of the higher required reserve ratio for demand deposits. As a result, the movement of funds from demand deposits into ATS accounts tended to reduce the required reserves in the banking system. This reduction in required reserves, as expected, led to increases in M1B and M2, and partially offset the

In 1982 this measure was changed to exclude some money warket mutual fund balances, Only general purpose and broker/ dealer balances are included.

4The primary reason for ignoring the grow th of $\mathrm{M} 2$ in 1981 is that it is not closely related to spending or inflation. For example, $\mathrm{M} 2$ growth slowed steadily from 1976 to 1980 , while spendeng and inftation aceelerated. In 1980-81, $\mathrm{M} 2$ growth accelerated, while inflation and spending began to slow. The correlation coefficient for the growth of $\mathrm{M} 2$ and GNP measured for over fourtalarter periods ending in each quarter from $/ / 1978$ to IV/1981 is only 0.07 indicating no relationship what soever. For more detailed analyses, see Keith M. Cartson and Scott E. Mein, "Monetary Aggregates as Monetary Indicators," this Review (November 1980), pp. 12-21; and R. W. Hafer, "Much Ado About M2," this Revieu: (October 1981), pp 13-18

${ }^{5}$ The legislation permitting nationwide ATS also extended NOW accounts to New York State beginning in November 1978, and New Jersey beginning in late 1979. Previous legislation allowed Now accounts in Commecticut, Mane, Massachusetts, New Hampshre, Rhode Island and Vemont.

${ }^{6}$ Both old Ml and MLA include currency in the hands of non-bank public and demand deposits at commercia banks. Old MI included aeposits of foreign official institutions as well, M1B is MA plus other checkable deposits at all financial institutions including ATS and NoW balances. decline in old MI and M1A caused by the shift to ATS deposits.

From October 1978 to October 1979, other checkable deposits (largely NOW accounts in New England, New Jersey and New York, and ATS deposits) increased from 2.5 percent to 6.3 percent of total checkable deposits. This shift slowed M1A growth by about 2.4 percentage points and raised M1B growth by about 0.5 percentage points from what otherwise would have occurred. ${ }^{8}$ MIA grew only 4.8 percent from October 1978 to October 1979 , about the sane as the old measure of $\mathrm{M} 1$, which grew 5.2 percent but considerably slower than the 7.9 percent growth of old M1 over the prior two years. M1B, however, grew 7.9 percent over the same period, the same rate of growth that it and the old measure of $\mathrm{Ml}$ registered over the prior two years.

The differing effects of the introduction of ATS accounts on the grow th of the monetary aggregates were important in assessing monetary policy as well. The growth of M1B did not slow during the first year of ATS; it continued, instead, at the record pace of expansion of the prior two years. Thus, judged by this measure, the influence of monetary aggregates on total spending and inflation remained un changed. In fact, inflation continued the upward spiral set in motion by the acceleration of money stock growth that began in mid-1976. Similarly, nominal GNP grew at an 11 percent rate from III/ 1978 to III/1979, little changed from its 11.9 percent rate over the prior four quarters. If one had focused upon old Ml or MIA developments, however, the direction of monetary actions would have appeared extremely restrictive. Consequently, a sharp reversal of both rapid GNP growth and accelerating inflation would have been expected. ${ }^{9}$ Neither, in fact, oceurred.

\footnotetext{
TWen ATS was introduced in November 1978 , the monetary aggregate measures MIA and MIB were not in use. The aggregate measure M1A, however, is little different from the old measure MI. The analysis of the effects of ATS on an MIA and MIB aggregate are described more fully by John A. Tatom and Richard W. Iang, "Automatic Transfers and the Money Supply Process," this Review (Februafy 1979), pp. 2-10.

${ }^{8}$ See Tatom and Lang:"Automatic Transfers," pp. 7-9.

"Shift adjustment of MIB makes little difference in the assessment of monetary policy in 1978-79. If 30 percent of ATS balances were considered idte savings balances, az appropriately adjusted MIB would have grown by 7.0 percent from October 1978 to October 1979, less then 1 percent below actual MIB growth. See Tatom and Lang, "Automatic Traxsfers," p. 7, especially footnote 14 . This difference would have little effect on inflation or spending developments in 1979. The shift to ATS was not large enough to provide even a weak test of whether MIB should be shiftadjusted, bat it did raise the issue.
} 
The proportion of checkable deposits held in other checkable deposits continued to rise after the first year of transition to ATS. From October 1979 to October 1980 , the ratio rose from 6.3 percent to 8.5 percent; by December 1980 , it had reached 9.1 percent. With the introduction of nationwide NOW accounts in January 1981, however, this proportion skyrocketed: by December 1981, it had climbed to 24.6 percent. Such a large shift produced large differences in growth rates between $\mathrm{MLB}$ and $\mathrm{MLA}$, and between M1B and a shift-adjusted MIB.

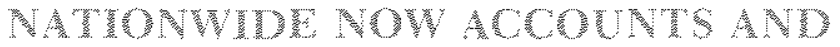

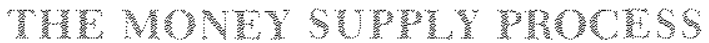

The introduction of nationwide NOW accounts affected the growth of monetary aggregates some what differently than did ATS accounts. New NOW accounts at all financial institutions were immediately subject to a 3 percent reserve requirement on the first $\$ 25$ million of these balances (an indexed threshold that changes every January beginning in 1982) and a 12 percent requirement on transactions balances in excess of this. The reserve requirement for new NOW accounts exceeds those for other transaction accounts at non-member financial institutions until the phase-in of reserve requirements on other transactions balances is completed in 1987. Thus, shifts of other transaction accounts or personal savings balances at these institutions to NOW accounts will raise required reserves.

Under the phase-down of reserve requirements on demand deposits at member banks, reserve requirements on demand deposits initially exceeded, at some banks, even the top reserve requirement ( 12 percent) for NOW balances, so a shift of funds to NoW accounts could have increased reserve requirements. At the same time, the reserve requirement on personal savings at member banks was lower than the minimum on NOW balances, so a shift from these funds raised reserve requirements. The important point, however, is that there was no systematic shift of checkable deposits to lower reserve deposit categories as was the case with ATS when checkable deposits moved into "savings balances" and thereby raised the M1B multiplier.

The principal effect of the transition to nationwide NOW accounts on the growth of specific monetary aggregates is definitional. That is, as NOW accounts are increased by switching funds from balances included in an aggregate like MlA that excludes
Now balances, the aggregate will decline relative to monetary aggregates such as M1B or M2 that include both the source of the funds and the newly created NOW deposits. The required reserve ratio reduction associated with ATS does not occur with NOW accounts so that no unusual rise in the MIB multiplier occurs as a result. Moreover, most of any reserve requirement increase associated with a shift to NOW accounts is due to new reserve requirements on those funds. Given the source base, the effect of such a reserve requirement increase on monetary aggregates is reflected in a reduction in the adjusted monetary base (the source base adjusted for reserve requirement changes) instead of the money multiplier. Thus, if the level or growth rate of the adjusted monetary base is unchanged, there is no positive effect of a shift to NOW accounts on the level or growth of M1B or M2.

\section{SW}

The shift-adjusted MIB measure was introduced in Chairman Volcker's report to Congress on monetary policy on February 25, 1981.10 Shift-adjusted MIB is simply MIB minus an estimate of the other checkable deposit account balances that originate from shifts of non-demand deposit funds. The conceptual rationale for this measure is to achieve a "purer" measure of transactions balances by remov" ing balances that previously had been held for nontransaction motives. It was estimated that 22.5 percent of seasonally unadjusted other checkable deposit increases were associated with shifts from deposits other than demand in January 1981; this figure rose to 27.5 percent in subsequent months.

The estimate of the size of the shift is based on several surveys of depository institutions and households and econometric techniques. The depository institutions sampled included $100 \mathrm{com}-$ mercial banks which provided data on the sources of new NOW balances in January-April of 1981. In May 1981, 400 banks were sampled. A sample of 100 savings and loan associations was conducted in January, March and May. In addition, a sample of about 700 households provided survey information

\footnotetext{
"See Patul A. Volker, "Monetary Policy Report to Congress," Federal Reserve Bulletin (March 1981), pp. 195-208. In Mareh the Fed began releasing information on shift-adjusted MIB in footrotes to the Federal Reserve Statistical Release H.6. A Fuller discassion of the adjustment was presented in the May 15, 1981, H.6 release and in "Recent Revisions of the Money Stock" Fedetal Reserve Bulletin (July 1981), pp. 539-42. Beginning May 22, 1981, montlly data on M1B shiftadjusted began to appear in table $\mathrm{I}$ of the $\mathrm{H} .6$ release.
} 


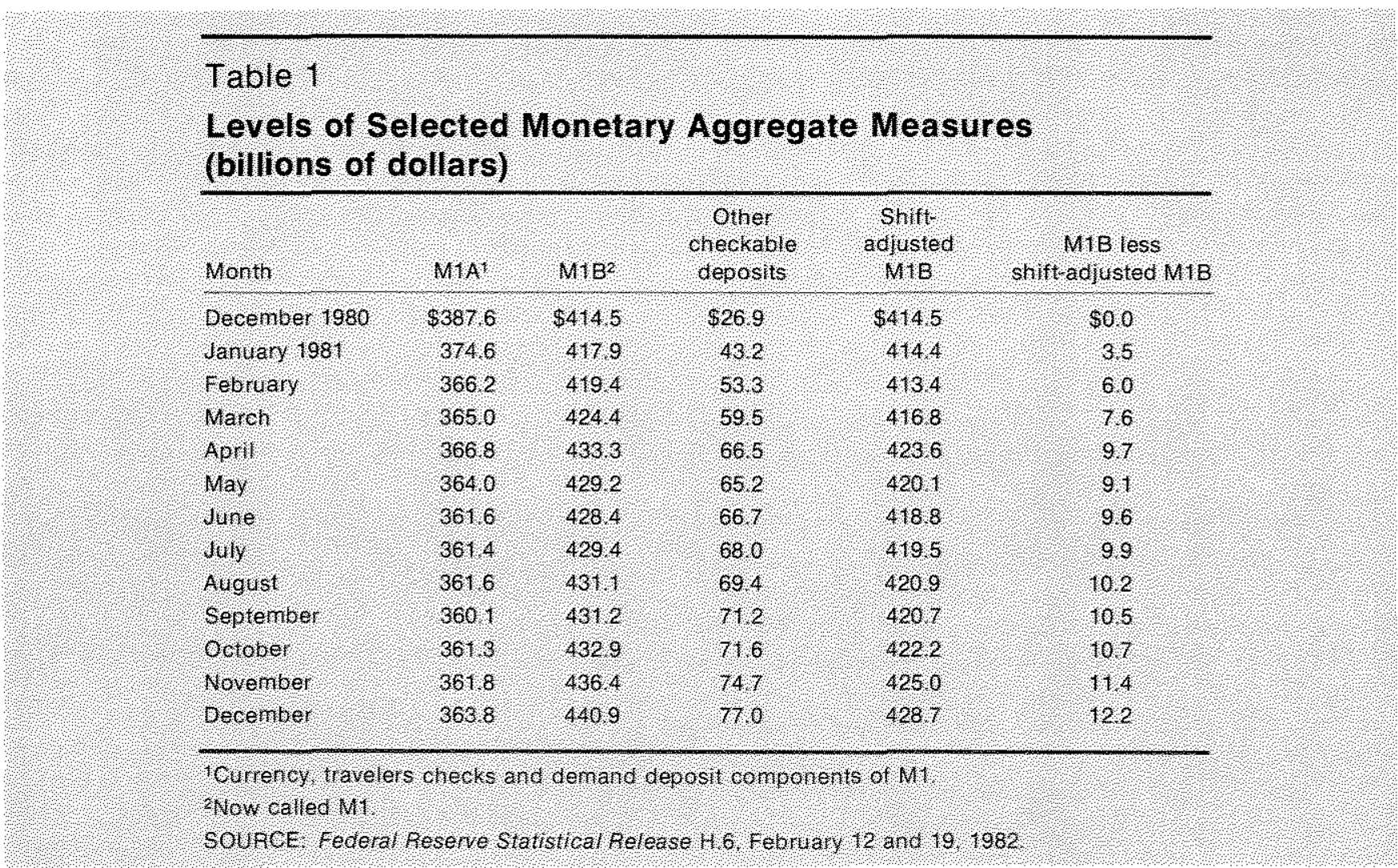

to the Survey Research Center of the University of Michigan in February, March and April. In June, the Center surveyed 5,000 more households. Finally, a statistical estimate of the simple linear relationship of changes in other checkable deposits to changes in demand deposits was conducted using eross-section weekly data for 9,000 weekly reporting banks.

The effect of the shift adjustment of M1B in 1981 is shown in table 1 . The difference botween MIA and M1B is other checkable deposits. The difference between shift-adjusted MIB and MLB is the imputed increment of other checkable deposits that arose from non-transactions balances (for the purpose of computing shift-adjusted MIB, all other checkable deposits prior to 1981 are treated as transactions balances). Other checkable deposits surged upward by $\$ 50.2$ billion from December 1980 to December 1981 , but $\$ 12.2$ billion of this increase is estimated to have come from non-transactions balances, according to the Board staff.

The increase in NOW accounts and its subsequent impact on the monetary aggregates were greatest from December 1980 to April 1981. Table 2 shows the annual growth rates of actual and shift-adjusted M1B for each month of 1981 . The differences in the growth rates are quite large from January to April, but the growth rates are similar thereater. From Decenber 1980 to April $1981, \mathrm{MlB}$ grew at a 14.2 percent average annual mate, 7.5 percentage points faster than shift-adjusted MlB. From April to December $1981, \mathrm{M} 1 \mathrm{~B}$ slowed to a 2.6 percent ate of increase and shift-adjusted MIB slowed to a 1.8 percent rate, a difference of only 0.8 percentage points.

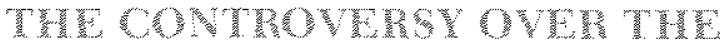

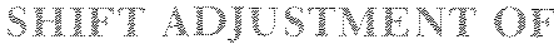

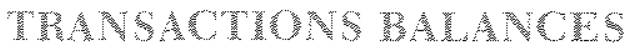

Whether the shift adjustment of M1B is useful in conducting and assessing monetary policy is essentially an empirical issue. Proponents of removing some of the NOW account from the narow monetary aggregate $M I B$ argue that these balances are not transactions balances since they were shifted from savings. These "idle" balances, they argue, are held in NOW accounts smply to satisly minimum balance requirements." Critics of shift adjustment readily

\footnotetext{
"Michad Bazdarch, "Has the Fed Been Too Tight" Anerich Banke, May 28, 1981, pp. 4 and 8, argues that the shift adjustment was andersteted by the Boand so that "true" money grew even slowe than the reported shiftadjusted measures.
} 


\begin{tabular}{|c|c|c|c|}
\hline \multicolumn{4}{|c|}{ 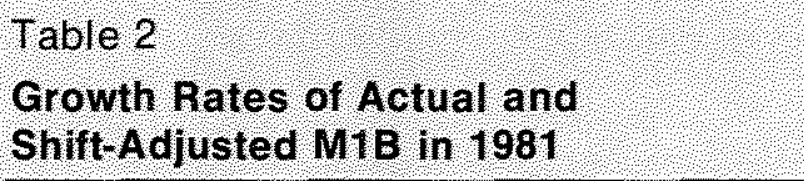 } \\
\hline Month & Mis & Shittadusted MTB & bifference \\
\hline Januart & $100 \%$ & $0.3 \%$ & $106 \%$ \\
\hline rebruars & 4,4 & 2.9 & 73 \\
\hline Mardt, & 153 & 108 & 50 \\
\hline AorI & 28.3 & 214 & 6.9 \\
\hline Nov & 10.0 & 9.5 & 43 \\
\hline done & 42, & \$? & 1,6 \\
\hline wey? & ? 6 & 20 & 0.6 \\
\hline Algust & 4.9 & 4,1 & 08 \\
\hline Septentiber & 0.3 & 40.6 & 09 \\
\hline Oclobel & 4.8 & 4.4 & 04 \\
\hline Novernber & 10.1 & 8.3 & 18 \\
\hline Decenber? & 428 & 440 & 18 \\
\hline
\end{tabular}

admit that such idle balances exist. They point out, however, that idle balances have always been held in transaction accounts without obvious or perverse effects on the "moneyness" of the total transactions balances.

Moreover, estimates of the proportion of other checkable deposits that shifted from nontransactions balances are flawed. Suppose an individual opens a NOW account by transfering only savings deposits. This would not demonstrate that the NOW balance is not a transaction balance. Indeed, the individual could write checks only on the NOW account while maintaining, during some transition period, an existing demand deposit balance to allow outstanding checks to clear before closing the account. The remaining demand deposit funds could then be switched back to savings. Alternatively, an individual could use currency to opern a NOW deposit and rebuild currency holdings with funds that would formerly have been deposited in a demand deposit account.

The source of the initial funds used to open a Now account, whether from currency, from demand deposits or from some savings medium at a financial institution, is irrelevant in determining whether the full amount of some fraction there of should be counted as money. What matters is whether the optimal holdings of financial assets such as currency, checkable deposits, or savings balances are alfected by NOW deposits. The initial transaction con* sidered alone does not reveal whether holdings of checkable deposits have been artificially inflated by funds held for saving purposes or, equally important, whether holdings of such inflated balances have affected the relationship of spending to measured money holdings.

To correctly assess the extent to which recent financial innovations have affected the quantity or quality of transactions balances, one must examine whether the fundamental relationships that affect the composition and use of money have been altered by the inclusion of all other checkable deposits in a narrow aggregate measure. Three such relationships are examined below: the demand for currency relative to checkable deposits, the ratio of debits against checkable deposits to the average level of checkable deposits (turnover), and the velocity of money.

\section{The Curreng Ratio}

An important determinant of the money multiplier and, hence, monetary aggregates, is the currency ratio, the holdings of currency relative to checkable deposits. Prior to the financial innovations that allow more explicit interest payments, this ratio was measured as the ratio of currency to demand deposits. Since these financial innovations, the relevant aggregate for assessing currency demand has been the portion of total checkable deposits that is transactions balances.

This ratio is of interest for two reasons. First, cumency holdings are part of the monetary base. Given the monetary base, changes in the currency held outside of financial institutions are mirrored in offetting changes in the base holdings (reserves) of these institutions. Changes in the reserves of financial institutions, in tum, affect their ability to supply the deposit components of monetary aggregates. Thus, movements in currency demand affect the relationship between the monetary base and the stock of monetary aggregates.

Second, currency is a transactions medium. Its matio to checkable deposits indicates the relative attractiveness of currency as money. The usefulness of currency and transfers of finds through financial institutions in facilitating exchanges are not identical. Further, the types of exchanges for which currency or checkable deposits are superior are not necessarily equally responsive to the growth of overall 
economic activity or spending. ${ }^{12}$ Thus, economic theory indicates that, given the technology of the payments process and portfolio preferences, the ratio of currency to checkable deposits should depend on the relative cost of holding and using currency in transactions and on movements in real income.

Now if some portion of checkable deposits are suddenly held for reasons unrelated to their usefulness in transactions, then the currency ratio that uses total checkable deposits in its denominator should decline relative to one with only transactions balances in the denominator. Thus, if a shift adjustment of M1B is appropriate, one should observe an unusual downward movement of the currency ratio without adjustments for the shift. ${ }^{13}$ This, in turn, should result in an unusual rise in the money multiplier, the link between the monetary base and all monetary aggregates (not shift adjusted). ${ }^{14}$

There were, however, no unusual movements in the ratio of currency to total checkable deposits in 1981. The ratio did not decline sharply with the introduction of NOW accounts. At the end of 1980 , the ratio stood at 39.02 percent. It rose to 39.12 percent in the first quarter of 1981 , fell slightly in the second quarter to 38.93 percent, rose to 39.52 percent in the third quarter and fell to 39.33 percent in the fourth quarter. On an annual average basis, the ratio was 39.23 percent in 1981 , little different from the 39.10 percent average in the prior year.

The ratio of total checkable deposits to shiftadjusted total checkable deposits rose from $1.019 \mathrm{in}$ the first quarter of 1981 to 1.032 in the second quarter, 1.035 in the third and 1.038 in the final

\footnotetext{
${ }^{12} \mathrm{~A}$ model of the currency matio that emphasizes the positive relationship of relative currency demand to interest rates and the inverse relationship with real income growth is presented in the appendix to the article. This model is ased to assess whether shifts of non-transactions balances to other checkable deposits have affected curency demand relative to other transactions balances.

13To the extent that natomwide NOW accounts offered an opportunity for lower-cost checkable teposits, the ratio of currency to total checkable deposits would be expected to deeline somewhat. Thus, a decline in this ratio would not prove that these checkable cleposits are inflated by the inclusion of some non-transactions balances. The eqidence presented in the appendix suggests that theze were no unusual declines in this ratio in 1981 for either reason.

${ }^{14}$ The MLB multiplier rose 0.6 percent from the fouth quarter of 1980 to the fourth quarter of 1981 , which is not umusual. Movements in the multiples are primarily due to currency ratio variation. The money mul tiplier movements are not explored in detail here since the currency ratio is.
}

quarter of 1981. If total checkable deposits overstated transactions balances by about 2 percent to 4 percent during the year, the currency ratio (measured relative to total checkable deposits) should have fallen by the same amount. In fact, the ratio rose slightly in 1981.

A shift-adjusted currency ratio can be constructed for 1981 by computing the ratio of currency to adjusted checkable deposits (total checkable deposits less the estimate of non-transactions balances). This shift-adjusted ratio rose sharply in 1981 so that in the fouth quarter of the year, it was 4.6 percent larger than the currency ratio at the end of 1980 . Such a sharp rise in the currency ratio has been exceeded in only two periods since 1960: from mid-1973 through 1976, when the currency ratio rose at a 5.2 percent rate, and in mid-1980, when a change in the composition of demand for liquid transactions balances caused the ratio to temporarily surge upward at a 16.6 percent annual rate. Excluding these periods, the mean growth rate of the currency ratio (unadjusted) for four-quarter periods from $\mathrm{V} / 1960$ to IV/ 1980 was 1.4 percent, while the standard deviation of the growth rate was 1.7 percentage points. The surge in the shift-adjusted ratio in 1981 was almost two standard deviations higher than this mean growth rate.

The unusual surge of such a shift-adjusted currency ratio suggests that the adjustment to remove non-transactions balances was too large. Indeed, this conclusion is supported by the statistical analysis in the appendix to this article. The currency ratio movements after the third quarter of 1978 (the quarter before the introduction of ATS accounts) are well explained by a model of currency demand relative to all other transactions balances, a model that also explains the curency ratio before that time. The surge in the currency ratio adjusted for the shift to NOW accounts is due to the adjustment procedure itself, artificially pushing up the ratio.

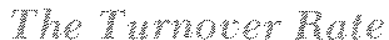

Another ratio that indicates the use of deposits for transactions purposes is the turnover rate, the ratio of deposit account debits to the average level of deposits. If the shift-adjustment argument is valid, the inclusion of a large spurt of non-transactions balances in measures of checkable deposits should reduce the 


\section{Chart 1}

\section{Transactions Account Turnover Ratios}

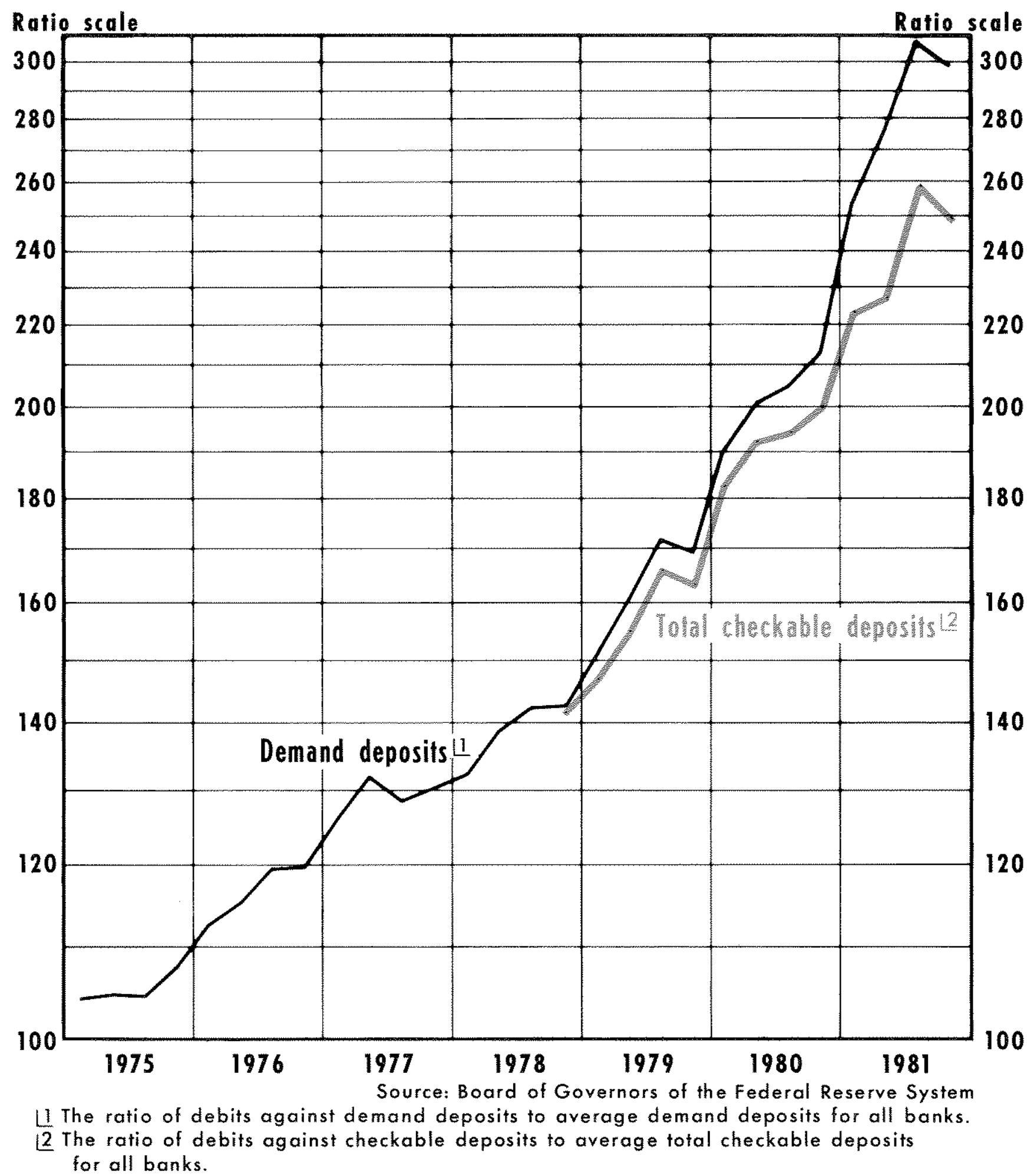


turnover rates of such deposits. ${ }^{15}$ Chart 1 shows the quarterly average of the turnover rate at all commercial banks for demand deposits since 1975 and all checkable deposits since 1977 . The tumover ratio for total checkable deposits is measured by dividing debits on demand deposits and ATS/NOW accounts by the total of such deposits. On average, this ratio actually accelerated in 1981, rather than declining as the shift-adjustment argument would suggest.

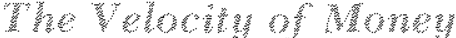

A final piece of evidence on shift adjustment concerns another ratio, the relationship of the nation's nominal gross national product (GNP) to the money stock $(\mathrm{M})$, or velocity $\left(\mathrm{V}=\frac{\mathrm{GNP}}{\mathrm{M}}\right)$. This is perhaps the most important ratio to use in assessing the impact, if any, of financial innovations on the measure of money and the assessment of monetary policy actions. If the money stock were artificially inflated by non-transactions balances, a policy to achieve a given level of $\mathrm{M}$ would bring about a lower level of spending (GNP) than desired or predicted by past velocity relationships. Monetary policy in 1981 focused on shift-adjusted $\mathrm{M} 1 \mathrm{~B}$, rather than M1B, because the velocity of MIB was expected to decline relative to its prior experience. In particular, existing historical relationships were expected to be more applicable to the adjusted M1B. Actual MlB growth was expected to be 2 to 3 percentage points faster than that targeted for adjusted MIB, reflecting this innovation-induced reduction in the velocity of M1B and its growth rate for the year.

\footnotetext{
15 One could argue that the observed tamover of ATS and NOW balances is much lower than that of demand deposits, providing evidence that ATS and NOW balances are not money to the same degree as demand deposits. The lower tumover rate is not starprising, however, for two reasons. First, NOW and ATS accomts appeal most to customers that would have low tmmover if their transactions balances were in demand deposits. This oceurs because a prominent fom of implicit interest payments on demand deposits is the remission of service charges. Thus, the introduction of explicit interest on transw actions balances would not change the incentives faced by depositors recenving competitive implicit interest. Holders of demand deposits whose implicit interest exceds the service charges on their balances cannot receive the difference as an explicit interest payment as they can on ATS or NOW balances. These customers tend to be those with relatively low tumover acconts, and they are the customers with the incentive to switch their holdings. The shifting of their funds from demand deposits to Now accounts should lead the tumover ratio of total checkable deposts to bo the same but should force that of demand deposits to surge up. That, in fact, is what appears to occar in chate 1 .
}

In fact, the opposite occurred. The behavior of $M 1 B$ velocity was not at all unusual in 1981 . For the four quarters of 1981 , M1B velocity expanded at a 4.6 percent rate, faster than the 2.0 percent rate of increase in the four quarters of 1980 and faster than the 3.1 percent average rate of expansion from 1955 through 1980. ${ }^{16}$ Thus, the behavior of M $1 B$ velocity in 1981 does not support the expectations of the proponents of shift adjustment (see chart 2).

Of course, since shift-adjusted M1B grew slower in 1981 than actual MIB, its velocity behavior was unusual. The velocity of adjusted MIB surged upward at a 7.4 percent rate from the fourth quarter of 1980 to the fourth quarter of 1981. This surge exceeds the growth of M1B velocity for every fourquarter period since 1959. From 1960 to the end of 1980 , the mean growth rate of velocity for fourquarter periods was 3.1 percent with a standard deviation of 1.58 percent. On this basis, the 1981 rise in the velocity of adjusted $M 1 B$ was a statistically significant departure from the past behavior of M1B, while the rise in actual M1B velocity was not. ${ }^{17}$ This suggests that the shift-adjusted measure of velocity was seriously biased upward by the removal of some transactions balances from M1B. ${ }^{18}$

\footnotetext{
16The uptick in MIB velocity growth arises from two factors. Finst, whenever money growth slows, velocity growth temporarily offsets some of its decrease by speeding up and subsequently slowing temporarily so that velocity growth retums to its prion trend. During the four cuarters of $1981, \mathrm{M} 1 \mathrm{~B}$ growth slowed to 5.0 percent from a 7.3 percent rate of increase over the four guarters of 1980 . Second, the $1979-80$ energy price increases retarded GNP growth in 1980 and accelerated it in 1981. See John A. T"atom, "Energy Prices and Short-Ran Economic Performance," this Review (January 1981), pp. 13-17. In contrast, Bennett and Bisigramo, "Apples, Onnges, and Money: 11, p. 3 , apparently believe the velocity of $\mathrm{MIB}$ accelerated to an unwstal extent in 1981 due to "the public's increasing sophis. tication in managing idle transactions balances."
}

17The significant surge is especially marked in the first wo quarters of 1981 when the shift adjustment affected the growth of M1B most. During those two quaters, shiftadjusted MiB velocity rose at a 9.1 percent rate, signiffeantly above the 3.1 percent mean fwo-gmarter mate of growth of MiB velocity from III/1959 to IV/1980 (standard erros $=2.54$ percent), while actual $M 1 B$ velocity rose only half as fast.

18 Some propenents of a shift adjustment reman undanted by such aberations. For example, some observers simply daim that the masual surge in the velocity of adiacted Mib is evidence that the demand for "money" shifted downward by an amount that, by sheer coincidence, is almost exactly the amount of money taken out by shif adjustment. See, for example, John P. Judd and Brian Motley, "Innovation and Monefaty Policy: $\mathrm{E}$, Federal Reserve Bank of San Francisco Weehly Letter September 1, 1981; and David E. Lindsey, "Nonbor wed Reserve Tarreting and Monetary Control," in lmaroeing Monot stock Control: Problems, Solutions, and Consequences, forthoming proceedings from a conference cosponsored by The Genter for the Study of American Business and this Bank, October 30-31, 


\section{Chart 2}

The Velocity of Money

\section{GNP/Money Stock}

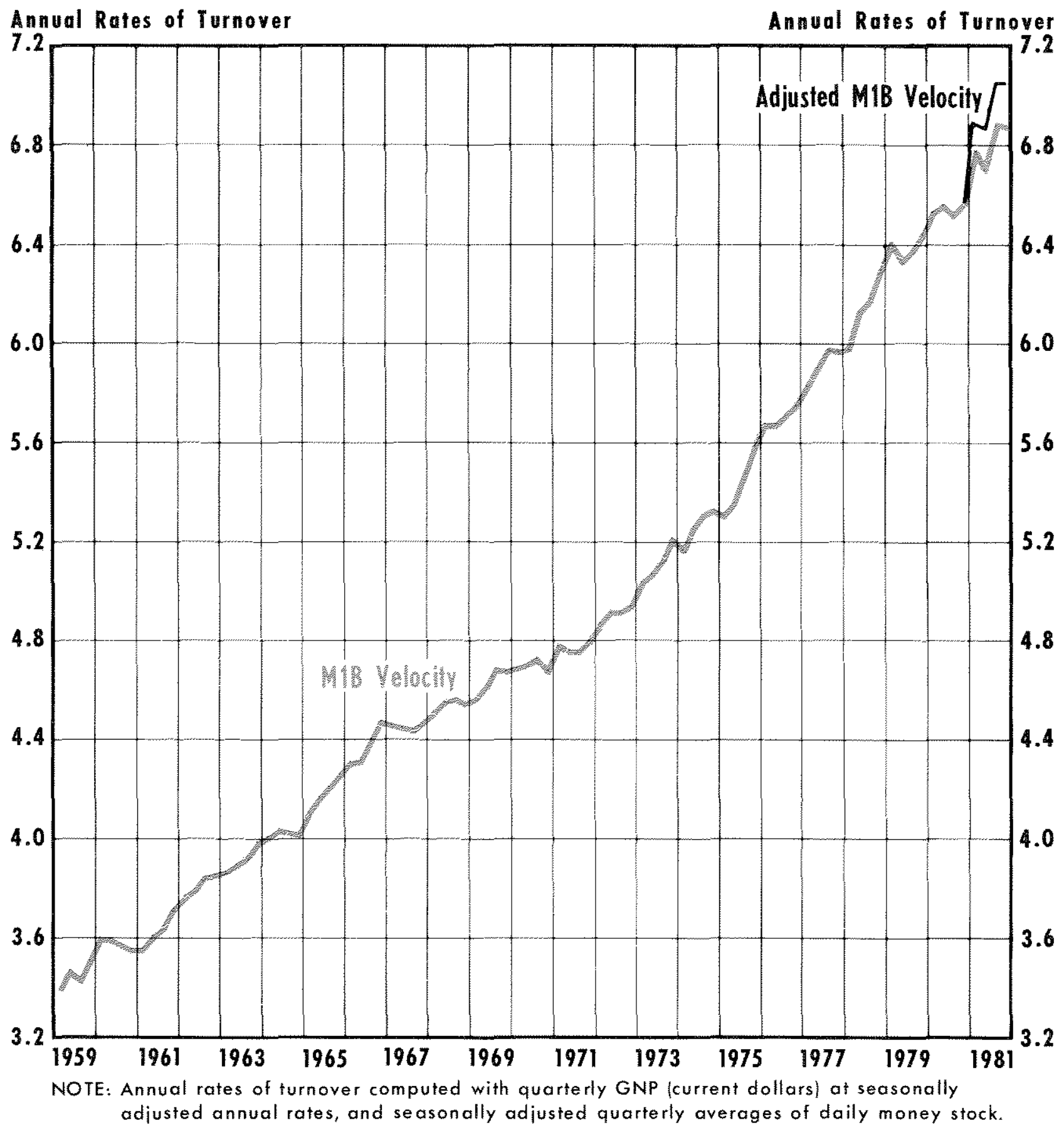

1981. Their argument is essentially that MIB adjustment removes $\mathrm{X}$ percent from the growth rate of $\mathrm{MIB}$, but that to assess the effects of monetary aggregate growth in 1981, one must add the $\mathrm{X}$ percent back; this is because of a mysterious "shift" that reduces the demand for money, not dae to the questionable shift adjustment of money. Presumably, the same response could be made to the evidence above for the currency ratio or tumover rate. 


\section{GONGI}

Analysts interested in determining the stance of monetary policy and assessing the likely response of spending and inflation to policy actions generaly have focused on the behavior of a narrow monetary aggregate. The experience last year posed problems for analysts because there were three potential narrow aggregates from which to choose: MIA, MIB and shift-adjusted MIB. It was generally conceded that new financial innovations made MlA virtually obsolete as a useful measure of monetary actions influencing spending and prices. The choice between MlB and shift-adjusted MlB, however, can only be determined by examining whether fundamental relationships affecting the composition and use of money are altered by including all other checkable deposits in the measure of money,

Three different fundamental relationships were examined using both MLB and shift-adjusted MlB: the demand for currency relative to checkable deposits, the ratio of debits against checkable deposits to the average level of checkable deposits (turnover), and the velocity of money. All three measures indicate that, in $1981, \mathrm{M} 1 \mathrm{~B}$ showed no unusual departure from its nomal pattem of behavior. Instead, unusual behavior in the fundamental relationships occurred only when shift adjustments were made to checkable deposits and MIB.

The most important conclusion to be drawn from the above analysis is that spending and inflation reductions in 1981 and beyond cannot reasonably be expected to match the unprecedented decline in money stock growth measured by shift-adjusted $M 1 B$, th the growth of $M 1 B$ was reduced from a 7.3 percent rate for the four quarters of 1980 to a shiftadjusted 2.3 percent rate for the four quarters of 1981; moreover, the three-year growth rate for the period ending in the fourth quarter of each year fell from 7.6 percent in 1980 to 5.6 percent in 1981, in shift-adjusted terms. Such a decline in monetary growth would be the sharpest slowing since World War II.

The slowing in spending and inflation are more likely to match the slowing in the growth of actual M1B to a 5.0 percent rate for the four quarters of 1981 and to a trend rate of 6.6 percent. In each case, the restraint is about half as large as indicated by adjusted M1B.

\footnotetext{
${ }^{19}$ An analysis that uses adjusted MLB as the approprate indicator may be found in Congressional Budget Offee, The Prospects For Econonit Recovery, Febuary 1982 , pp. 6, 14 and 39-45.
} 


\section{Appendix}

\section{NOW Accounts, Shift Adjustment and the Currency Ratio}

This appendix examines a currency demand model derived from the FMP quarterly econometric model developed, in part, and used by the staff of the Federal Reserve Board of Govemors. This model contains separate equations for currency and demand deposits from which a currency ratio can be derived. The currency ratio model can be used to assess whether shifts of non-transactions balances to other checkable deposits have had significant effects on the demand for currency relative to the other transactions balances included in a narrow monetary aggregate. The results do not support the use of sh iftadjusted measures of checkable deposits. Instead, past empirical relationships remain stable when demand deposit measures are broadened to include all other checkable deposits.

In the model, the logarithm $(\log )$ of currency per dollar of personal consumption expenditures is re. lated to a constant, a lagged dependent variable, the current log of the 3-month Treasury bill rate, a time trend and a zero/one dummy for the period before and after the second quarter of 1960 . The $\log$ of demand deposits per dollar of GNP is related to: the log of the current federal funds rate; current and three lagged values of the $\log$ of the 3-month Treasury bill rate, the $\log$ of the commetcial bank passbook rate, and real GNP per capita; and a varying time trend that is broken at the third quarter of 1974, the third quarter of 1976 , the fourth quarter of 1977 , and the fourth quarter of $1978 .^{1}$ The implicit model of the currency-demand deposit ratio relates the $\log$ of the currency ratio to all of the right-handside variables above, and the log of the ratio of GNP

\footnotetext{
One could argue that the broken time trend is not appropriately considered to be a part of the structural specification of the FMP model, but rather is included to keep the demand deposit fanetion on trak and preserve efferency in estimating the structural paraneters. Their inclusion here, however, conden not bias the tests meported below as the broken trend wsed here ends before the test period, and the inprovement in the ft over the initial sample period obtained by iraluang the broken trend taises the power of structurat change tests.
}

to personal consumption expenditures (with a co. efficient constrained to unity).

This model was estimated using the generalized least-squares method with second-order autocorrelation adjustment for the period 1/1961-111/1978 but without the constraints imposed on right-hand-side variables that are used in the FMP model. This period was chosen to avoid the shift in the FMP currency equation in II/1960, and the period when other checkable deposits became a large share of total checkable deposits. The FMP variables that have a t-statistic less than unity were omitted. The resulting currency ratio estimate is (t-statistics in parentheses):

$$
\begin{aligned}
& \text { (1) } \ln (\mathrm{CDDD})_{2}=-1.776-0.134 \ln (\mathrm{X} / \mathrm{N})_{t}+0.023 \ln \mathrm{r}_{\mathrm{t}-1} \\
& (-4.38)(-2.14) \quad(3.93) \\
& +0.008 \ln r_{t-2}+0.017 \ln x_{t-33}+0.155 \ln (\mathrm{C} / \mathrm{PCE})_{t-1} \\
& \begin{array}{lll}
\text { (1.44) (3.00) } & (1.87)
\end{array} \\
& +0.004 \mathrm{~T} 1+0.013 \mathrm{~T} 2-0.004 \mathrm{~T} 3-0.010 \mathrm{~T} 4 \\
& \begin{array}{lll}
(7.10) \quad(8.51) \quad(-1.46) \quad(-2.47)
\end{array} \\
& \overline{\mathbf{R}}^{2}=0.968 \quad \mathrm{DW}=1.98 \quad \hat{\rho}_{1}=1.10 \\
& \mathrm{SF}=0.0045 \quad \mathrm{~h}=0.15 \quad \hat{\rho}_{2}=-0.30
\end{aligned}
$$

where $\mathrm{C}$ is currency, DD is demand deposits, $\mathrm{X} / \mathrm{N}$ is real GNP per capita, $r$ is the 3 -month Treasury bill rate, $\mathrm{PCE}$ is personal consumption expenditures, $\mathrm{T} 1$ is an unbroken time trend, $\mathrm{T} 2$ is a time trend that is zero until II/1974 and increases by one thereafter, and $\mathrm{T} 3$ and $\mathrm{T} 4$ are time trends that increase by one from zero in IV/1976 and IV/1977, respectively. ${ }^{2}$

The introduction of ATS/NOW accounts after III/ 1978 presumably changes the specification of the demand for currency. In particular, the notion of competing transactions balances must be broadened to account for this innovation. There are two hypotheses tested here. The first is that total checkable deposits adjusted for the estimate of the shift of non-

When total checkable deposits are used in the denominator of equation 1 , the resulting equation is identical to that reported. 
transactions balances to NOW accounts is the relevant measure of transactions balances that compete with currency as a useful medium of exchange. The alternative hypothesis is that all checkable deposits are relevant for measuring transactions balances that serve as a substitute for currency.

If a shift in currency demand behavior has occurred so that the relevant measure of competing transactions balances is adjusted checkable deposits $(A C D)$, which equals total checkable deposits less the estimate of non-transactions balances, then the $\log$ of $(\mathrm{ACD} / \mathrm{DD})_{\mathrm{t}}$ should be added to the right-hand side of equation 1 when the sample period is extended into 1981. When this variable is added, ats coefficient should be one, if currency demand relative to checkable deposits has been unchanged but such deposits are shift adjusted in 1981.

To examine the hypothesis that currency demand measured relative to checkable deposits after shift adjustment is the appropriate measure for capturing transactions balances, equation 1 is re-estimated for the period $\mathrm{V} / 1961$ - IV/1981 with this added variable and the inclusion of a dummy variable, $D 6=1$ in II/1980 and zero otherwise, to capture the temporary surge in currency demand associated with the credit control program in that quarter ${ }^{3}$ The estimate is:

$$
\begin{aligned}
& \text { (2) } \ln (\mathrm{C} / \mathrm{DD})_{1}=-1.390-0.098 \ln (\mathrm{X} / \mathrm{N})_{+}+0.024 \ln r_{t} \\
& (-3.57)(-1.65) \\
& (4.22) \\
& +0.007 \ln r_{t-2}+0.017 \ln r_{t-3}+0.232 \ln (\mathrm{OPCE})_{t-1} \\
& \text { (1.37) } \\
& \text { (3.15) } \\
& \text { (2.90) } \\
& +0.004 \mathrm{~T} 1+0.013 \mathrm{~T} 2-0.006 \mathrm{~T} 3-0.008 \mathrm{~T} 4
\end{aligned}
$$

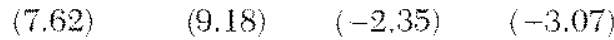

$$
\begin{aligned}
& +0.024 \mathrm{D} 6+1.271 \ln (\mathrm{ACD} / \mathrm{DD}) \\
& \text { (6.09) (16.87) }
\end{aligned}
$$

$\begin{array}{lll}\overline{\mathrm{R}}^{2}=0.991 & \mathrm{DW}=1.97 & \hat{\rho}_{1}=0.98 \\ \mathrm{SE}=0.0048 & \mathrm{~h}=0.22 & \hat{\rho}_{2}=-0.23\end{array}$

Both of the added variables are highly significant, and the other coefficients, as well as the summary statistics, are not significantly different from those in equation 1 . The last trend variable (T4) mentioned above for the FMP model was also added to the equation; this time trend is zero to III/1978, then increases by one in each subsequent quarter, and

\footnotetext{
Whis shift in the composition of the denand for money has been noted in the report by Robert Weintrub, "The Impact of the Federal Reserve Syatem's Monetary Poliches on the Nation's Feconony, "Second Report). Staff Report of the Sabcommittee on Domestic Monetary Policy of the Commitee on Banking, Finume and Urban Affirs, House of Representatives, 96 Como. 2 Sess, Government Printing Offee, December 1980 , p. 17.
}

presumably is in the FMP model to account for ATS and NOW shifts. The inclusion of this variable has no effect on the other coefficient estinates (for example, the coefficient on $\ln$ (ACD/DD) is 1.251 with a standard error of 0.083 ) or summary statistics, and it is not statistically significant $(t=0,54)$.

The shift-adjustment hypothesis implies that the coefficient for In (ACD/DD) should equal one. The standard error of the coefficient estimate is 0.0753 , so the t-statistic for the null hypothesis is 3.59 , and therefore the shift-adjustment hypothesis that the coefficient equals unity can be rejected. The ratio of currency to adjusted checkable deposits is significantly and positively related to the size of the shift into NOW and ATS accounts (ACD/DD) so that it appears artificially biased upward by the shift adjustment. ${ }^{4}$

At the other extreme, one can hypothesize that all other checkable deposits are transactions balances; that is, all other checkable deposits are competing transactions balances for assessing currency demand. To test this hypothesis, the log of the ratio of total checkable deposits (TCD) to demand deposits is added to equation 1 , and the other steps described for equation 2 are followed. The result is:

$$
\begin{aligned}
& \text { (3) } \ln (\mathrm{C} / \mathrm{DD})_{t}=-1.313-0.092 \ln (\mathrm{X} / \mathrm{N})_{3}+0.025 \ln \mathrm{r}_{t-1} \\
& (-3.28)(-1.53) \quad(4.27) \\
& +0.006 \ln x_{t-2}+0.018 \ln x_{-3}+0.25 \ln (\mathrm{CPCE})_{t-1} \\
& (1.16) \quad(3.12) \quad(3.06) \\
& +0.004 \mathrm{~T} 1+0.013 \mathrm{T2}-0.006 \mathrm{~T} 3-0.00 \mathrm{~T} 4 \\
& \begin{array}{llll}
(7.53) & (9.09) \quad(-2.28) \quad(-2.57)
\end{array} \\
& +0.02406+0.997 \ln (\mathrm{TCDOD}) \\
& \text { (5.93) (16.51) } \\
& \begin{array}{lll}
\overline{\mathrm{R}}=0.992 & \mathrm{DW}=1.97 & \hat{\rho}_{1}=0.97 \\
\mathrm{SH}=0.0049 & \mathrm{~h}=0.18 & \hat{\rho}_{2}=-0.22
\end{array}
\end{aligned}
$$

The fit of this equation is virtually identical to that of equation 2.5 In this case, however, the null hypothesis that the coefficient on the shift variable equals unity cannot be rejected the standard error of the coefficient for the shift variable is 0.0604 and the t-statistic for the null hypothes is is $t=-0.05$ ). Thus,

\footnotetext{
${ }^{4}$ When equation 2 is estimated with adjusted checkable deposits in the denominator, the elasticity of the currency mio with respect to the ratio of adjusted checkable deposits to demand deposits is $0.271(t=3.59)$, essentially the percentage of the shifting balances that has been removed.

5When the trend shift after WI/978 is included in equation 3 the earlier result holds. In purticular, the tmstatistic for the shift is 0.90 , and the coefficients and summaty statistes reported in equation 3 are not affected. The coefficient on the shift wariale

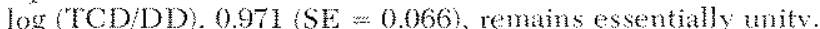


when the lefthand side is written as $\ln (\mathrm{C} / \mathrm{TCD})$, a shift variable is not significant (the coefficient on the shift variable is then -0.002 and its standard error is 0.06 , the right-hand side variables are the same as in equation 1 and the currency demand equation is stable. The F-test for the stability of equation 1 , including controls for the effects of the 1980 credit controls and the broadening of transactions deposits from demand deposits to total checkable deposits, can reject instability. The F-statistic for the additional observations in equation 3 is $F_{11}, 72=1.93$, below the critical $F$ of 2.50 for a 1 percent level of significance.
According to the currency-deposit relationship in the FMP model, NOW accounts (or other new types of transactions balances) do not cause a shift in the carrency-checkable deposit ratio when all checkable deposit balances are included. When a shift of non-transactions deposits into checkable deposits is taken into account, the shift creates a bias in estimates of currency demand that is directly related to the size of the adjustment. These results indicate, at least for this model, that there is no support for shift adjustments; where shift adjustments are used, offsetting shifts in relationships must be included to "wash out" the adjustment.

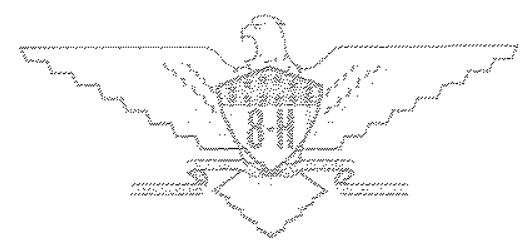

